\title{
Imaging blood vessels of the head and neck
}

\author{
R J Sellar
}

The modern era of blood vessel imaging began in 1929 when Forssmann injected himself with contrast medium through a large bore catheter. ${ }^{1}$ Although recognised to be a hazardous procedure the diagnostic ability of angiography was quickly appreciated and a whole new field of neurosurgery rapidly emerged. Dott in Edinburgh wrapped a cerebral aneurysm in $1932^{2}$ and Eastcott in London performed the first carotid endarterectomy in $1954 .^{3}$

While angiographic techniques have continued to improve, so has the appreciation of the risks; when the benefits of treatment are minimal, such as in patients with low grade carotid stenosis, the risks of angiography can outweigh its benefits. This has led to the search for less invasive modalities to image the blood vessels. This article reviews these new methods, particularly Doppler ultrasonography (DUS), magnetic resonance angiography (MRA), and CT. It also discusses what is the role for angiography other than its accepted use for vascular lesions in the head such as aneurysms and arteriovenous malformations. The remaining role of angiography in imaging the carotid bifurcation is the current subject of heated debate.

The intensity of this debate was recently increased by the North American Symptomatic Carotid Endarterectomy Trial (NASCET) $^{4}$ and the European Carotid Surgery Trial (ECST) ${ }^{5}$ both of which showed that $70 \%$ stenosis, when measured from an angiogram, could select a group of patients that benefited from carotid surgery but that non-invasive measurement, when performed as in NASCET, did not satisfactorily select these patients. ${ }^{6}$

\section{Measurements on the carotid arteries METHODOLOGICAL PROBLEMS}

Before reviewing the various methods of imaging the cerebral blood vessels it is important to understand that much of the controversy surrounding the investigation of patients, particularly those with arterioscleortic disease, relates to the different methods of measuring the disease that are used. Measurement of angiographic carotid stenosis can be performed in at least three different ways and further methods still are used to measure stenosis detected by other modalities.

In the first place it is unlikely that good correlation will exist between two methods based on different physical principles. Angiographic measurements are of the anatomical transverse diameter of the lumen of the artery. Doppler flow measurements are physiological and relate to the state of the circulation. The Doppler signal at one point in time depends not only on the vessel's cross sectional area (not merely its diameter), but also on cardiac output and peripheral resistance.

Secondly, the probable discrepancy between such differing methods of measurement becomes far greater when the stenosis is asymmetric. The peak velocity produced by a given diameter stenosis can differ by $30 \%$ depending on whether the stenosis is concentric or asymmetric. ${ }^{7}$

The third point relates to angiography; many studies, including NASCET, require two views for measurement of carotid stenosis. Often on one view (usually the anteroposterior) the stenosis is obscured due to overlap from the external carotid vessel. If this is the case there is a potential for considerable error in measuring percentage stenosis and even if three views are taken large errors may still occur. The figure shows that even if oblique and lateral projectives are available there can still be considerable error in estimating percentage stenosis. The variability of angiography between observers has not been fully tested. ${ }^{8}$ There have been studies of error in measurement of carotid stenosis between observers but unfortunately it is unethical to repeat the entire procedure. This is a pity because it would have highlighted the problem of limited views and almost certainly helped to standardise angiographic procedures.

Perhaps more surprising is that even within each imaging modality there is little standardisation of the methods of measurement. This is particularly true of measurement of angiographic stenosis. This has important consequences; the method used by NASCET ${ }^{4}$ was significantly different from that used by ECST. ${ }^{5}$ The denominator chosen by ECST was an imaginary diameter of the carotid bulb before it was diseased, whereas in NASCET it was the distal internal carotid artery at the point when the walls become parallel.

The difference in mensuration has recently been shown to result in an ECST measurement of $70 \%$ representing the same degree of stenosis as a NASCET measurement of $50 \% .{ }^{9}$ Because ECST produced a significant result for $70 \%$ and greater stenosis (these patients benefiting from surgery), it could be argued that the continuing NASCET trial may now be randomising the wrong group of patients in 
Effect of different views on degree of apparent carotid stenosis.
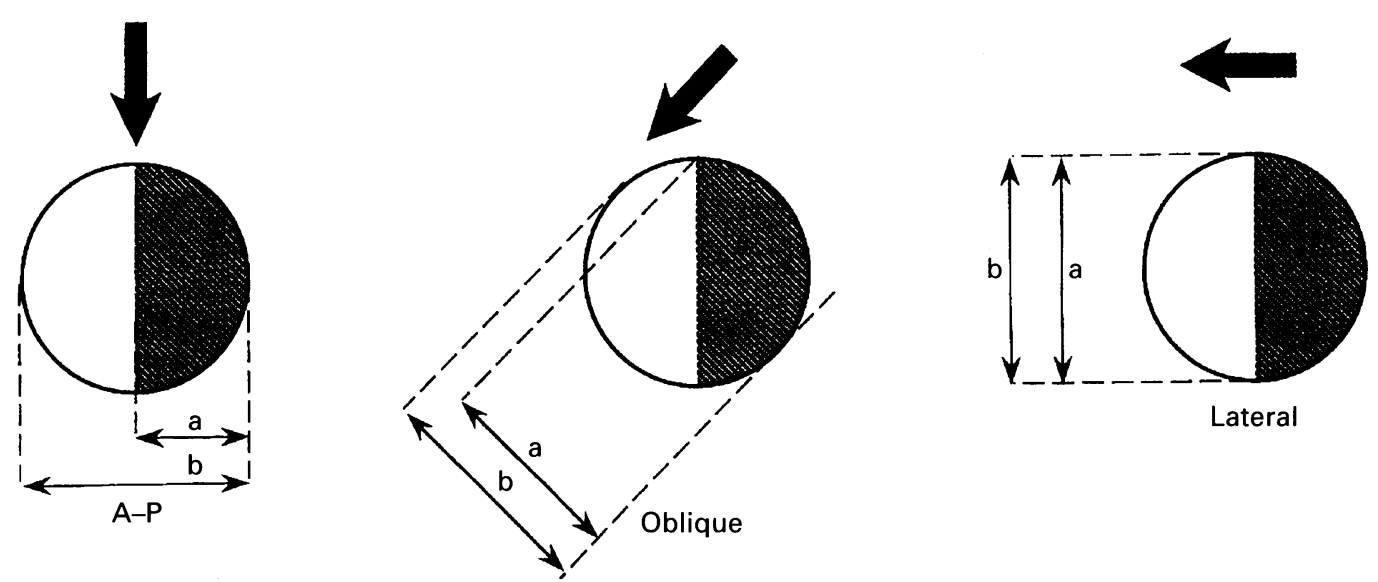

Indicates direction of $x$ ray beam

that the critical degree of stenosis is likely to be less than $50 \%$ NASCET stenosis rather than $70 \%$.

Finally DUS, MRA, and angiography are often compared from correlation coefficients but the use of coefficient statistics is totally inappropriate when comparing two measures that are not calibrated against a true value. ${ }^{10}$ There is a high correlation between foot size and height but this does not mean that the measurement of a neurosurgeon's foot will give you an accurate measure of his height. It is possible to obtain a high degree of correlation although one of the methods is highly inaccurate due to bias. Doppler ultrasonography machines vary considerably ${ }^{112}$ and it is probable that lack of calibration contributed significantly to the poor DUS results in multicentre trials.

In summary, unless the theoretical problems related to measurement are clearly understood, it is likely that the problems that non-invasive methods of investigating carotid disease have had in gaining credibility will continue.

\section{Carotid Doppler ultrasound (DUS)}

This review considers the non-invasive imaging techniques before the invasive ones. It is the safety of DUS that is one of its great advantages and it is a technique that has achieved widespread use as a screening test for carotid atherosclerosis. Carotid ultrasound was initially performed with continuous wave Doppler. Two separate transducers were used, one to transmit, the other to receive ultrasound signals. Doppler images were obtained, from which peak flow velocities could be calculated with the Doppler shift principle. ${ }^{13}$ Pulsed wave Doppler uses the same transducer to transmit and receive waves; discrete volumes can be sampled with this technique, and this improves depth resolution. The next major advance was the elegant combination of real time imaging
Doppler information called duplex ultrasonography. ${ }^{14}$ The stenosis could be measured from an image with calipers as well as assessed physiologically with Doppler.

The most recent development has been colour flow DUS, whereby flow information is colour coded and superimposed on the grey scale images. This reduces the time of the examination by rapidly pinpointing the pathological regions. The angle of insonation can now be electronically set to keep the Doppler measurements accurate.

\section{DUS CRITERIA FOR SIGNIFICANT CAROTID}

DISEASE

Various Doppler measures have been proposed in addition to the real time image measures for detecting significant stenosis. Peak systolic and peak diastolic velocity can be measured both in the common carotid artery, at, or just distal to the stenosis and in the distal internal carotid artery well beyond the stenotic area. These measures can be used on their own or expressed as ratios. Peak systolic flow velocity adjacent to the stenosis has been found to correlate well with angiographic stenosis in two studies. ${ }^{15}$ Examination of various diagnostic criteria showed peak systolic flow velocity to be the most straightforward measure with a $2 \cdot 25-2 \cdot 3 \mathrm{~m} / \mathrm{s}$ threshold being used to predict $70 \%$ angiographic stenosis.

Both these studies generated receiver operator characteristic curves, which are useful as they allow the clinician to decide what sensitivity and specificity are required for a particular clinical situation and to choose a threshold that is appropriate. (For screening purposes a peak systolic flow velocity of about $1.25 \mathrm{~m} / \mathrm{s}$ is typically used to select patients with $50 \%$ carotid stenosis.)

Several authors have found that in very severe stenosis the peak systolic flow velocity Doppler signal can decline and that peak diastolic flow is a more accurate method of detecting these patients. ${ }^{17}$ The diagnosis of carotid 
occlusion can be made by the absence of pulsation from the internal carotid artery, and the presence of echogenic material filling the lumen. Doppler signals will be absent and the distal artery may be reduced in diameter. ${ }^{14}$

\section{WHAT IS THE ROLE OF DUS?}

Can DUS be relied on not only as a screening test but as the only and definitive diagnostic test before surgery? This is a question that has caused much heated debate..$^{812}$ It is easiest to approach this subject historically.

Many authors in the early 1980 s found that there was high sensitivity, specificity, and accuracy in DUS as a technique for detecting carotid stenosis. A review by Cardullo et al of 16 studies concluded that DUS was $96 \%$ sensitive, $86 \%$ specific, and $91 \%$ accurate at detecting angiographic carotid stenosis greater than $50 \% .{ }^{18}$ The enthusiasm for DUS grew during the 1980 s so that by 1987 Goodison et $a l^{19}$ were claiming that the accuracy of DUS exceeded that of angiography; Hartnell, ${ }^{20}$ although conceding that it was difficult for clinicians to change old habits, said it was time that surgeons used only DUS preoperatively because it was better than angiography for detecting severe stenosis. This momentum came to an abrupt halt when the NASCET results were published. ${ }^{4}$ It was clear that $70 \%$ angiographic stenosis selected a group of patients that benefited from surgery but no equivalent Doppler measurements could satisfactorily select this group. Later the sonographic data was presented and the sensitivity for detecting $70 \%$ angiographic stenosis was only $59 \% .^{6}$ These data have subsequently been criticised on account of poor quality control. There were, however, other causes of failure of ultrasound to pass the acid test of a randomised prospective multicentre trial.

Firstly there has been a tendency to rewrite the early ultrasound data. Zweibel, in his excellent review of DUS of the cerebral arteries in $1992,{ }^{14}$ states that the accuracy of carotid artery measurements is high. $\mathrm{He}$ quotes five papers to support this, all surprisingly published around eight years before his review. ${ }^{21-25}$ The sensitivities range from $91-94 \%$ with equally impressive specificity and accuracies quoted (87-99\%) for detecting significant carotid stenosis. By far the largest series is his own with 393 vessels insonated. ${ }^{21}$ Because the common and external carotid arteries were assessed as well, in reality this means that 131 bifurcations in 78 patients were evaluated.

It is rewarding to look at this early paper in more detail and to quote the author's original comments: "the sensitivity level of HRS (high resolution sonography), CWD (continuous wave Doppler), and the combined procedures all were suboptimal for a screening study ( $72 \%$ CWD, $72 \%$ HRS, and $82 \%$ combined). If $50 \%$ decrease in diameter is considered to be the level at which carotid stenosis becomes haemodynamically significant, then these results cast doubt on the case of ultrasound as a screening procedure".

It is only if the studies that were of poor quality or in which the artery was wrongly localised are removed from the results that the sensitivities improve to acceptable levels. Ten years later, the same data were claimed by the author to show that DUS has a $94 \%$ sensitivity and $99 \%$ specificity for detecting $50 \%$ and greater stenosis and others went on to claim that DUS is so accurate that surgical decisions should be based on it.

More recent researchers have consistently achieved high sensitivities of $81 \%$ to $85 \%$ for DUS in detecting $50 \%$ stenosis but these are results achieved by specialised units on small numbers of patients. ${ }^{152627}$ Hunting et al have stated that if verification bias is taken into account sensitivities of greater than $70 \%$ will be difficult to achieve by DUS. ${ }^{15}$

Secondly, ultrasound is both highly operator and machine dependent; although colour flow has reduced the pitfalls for the operator, it still remains a highly skilled investigation. On account of the variability of results from different centres, doubt has been cast on its use for multicentre trials without proper calibration of the ultrasound equipment and certification of laboratories. ${ }^{11}$

Thirdly, there is no agreement as to which measurements should be used and considerable debate as to whether a battery of DUS tests including orbital plethysmography is required $^{28}$ or whether a single measure-for example, peak systolic flow velocity-is sufficient.

Finally the need for angiography before surgery has been underlined by two further studies. The first was from the NASCET Group describing an association between angiographic ulceration and increased risk of stroke, particularly in patients with very severe degrees of stenosis. ${ }^{29}$ The second was a recent study by Griffiths et al, ${ }^{32}$ which found concurrent intracranial disease in 26 out of a 100 consecutive patients referred for investigation of cerebrovascular disease. Eleven had aneurysms or arteriovenous malformations and 15 had tandem stenoses. There has been extensive debate on the subject of patients who have a second carotid stenosis typically situated in the carotid syphon.

Polak has stated that such tandem stenoses are rare, pointing out that they were present in only $2 \%$ of cases in NASCET and that in any case the decision regarding surgery or not is unaffected. ${ }^{8}$ The studies he quotes in support of his case are, however, totally inappropriate. Firstly, the presence of tandem lesions was a specific exclusion criteria of NASCET, ${ }^{4}$ so the incidence is likely to be low in this study! With respect to the second issue he cites Little et $a l^{33}$; this paper is concerned with the distinction of distal stenosis from flow artifacts rather than with the effect of tandem lesions on surgical decisions. Polak's defence of ultrasound in general is curious and is partly based on the argument that it must be good because its use is widespread. "Was it not performed in all ECST patients?" he asks. ${ }^{8}$ In fact, no ultrasound data at all were collected for the ECST trial. In summary, DUS has achieved widespread use as a screening test although it 
has only replaced angiography in a few centres where it is believed that the risks of angiography outweigh the benefits of accurate classification and knowledge of the intracranial circulation.

On the other hand the value of ultrasound as a screening test is established; using it in this way O'Leary and Polak were able to increase the incidence of haemodynamically significant stenosis in patients going on to angiography from $50 \%$ to $80 \% .{ }^{30}$ There are practical reasons why DUS is a good screening test for mild and moderate stenosis but less accurate in cases of severe stenosis. As the artery becomes progressively stenosed, the impedance of the plaque increases and this tends to cause blurring of the interfaces and reverberation artifact. Measurement of the stenosis with calipers is often difficult and ultrasound diagnosis is then dependent on the physiological data, typically the peak systolic velocity. ${ }^{30}$ When complete occlusion occurs the distinction from very tight stenosis has always been a problem for ultrasonographers and the external carotid may be mistaken for the internal carotid artery. ${ }^{31}$

A recent prospective study comparing DUS and MRA with conventional angiography by Houston et $a l^{27}$ showed that DUS correctly identified all of the angiographic stenosis of greater than $50 \%$ but misclassified $60 \%$ of patients with angiographic moderate stenosis $(50-80 \%$ in this series) as having severe stenosis and $37 \%$ of patients with angiographic occlusion were thought to have stenosed but patent carotid arteries. These findings confirm that DUS is an excellent screening test for $50 \%$ stenosis but has problems in classifying the more severe degrees and that angiography is required in patients for accurate classification of the severity of the stenosis.

IMAGING OF PLAQUE WITH ULTRASOUND

Ultrasound is the first of the imaging techniques to focus on other characteristics of plaque apart from its shape and size. Heavily calcified plaque is strongly echogenic. Fibrogenic plaque is also echogenic but relatively homogeneous whereas intraplaque haemorrhage results in heterogeneity within the plaque and areas that are anechoic. Some studies comparing the DUS detection of haemorrhage with surgical histology have been encouraging with sensitivities ranging from $72 \%$ to $74 \%$ and specificities of $79 \%$ to $80 \% .{ }^{14} 34$ Other studies showed no correlation, however, between DUS and histology. ${ }^{35}$ The hypothesis that intraplaque haemorrhage leads to intimal inflammation and secondary mural thrombus is supported by several studies reporting an increased risk of transient ischaemic attacks and infarction in patients with DUS plaque haemorrhage. Conversely, postmortem studies of asymptomatic subjects have shown a high incidence of ultraplaque haemorrhage. ${ }^{36}$ Hopefully, a larger prospective trial will show whether plaque morphology, particularly intraplaque haemorrhage, is indeed a risk factor.
TRANSCRANIAL DOPPLER (TCD)

This technique uses the thin temporal bone above the zygoma as a window to image the middle cerebral artery and the other vessels close to the circle of Willis. ${ }^{37}$

Now that colour flow information has been added, it has become an increasingly valuable technique for studying the intracranial circulation in a non-invasive manner. Applications include following subarachnoid haemorrhage when TCD can detect spasm before clinical deterioration. We have found a $20 \%$ increase in peak systolic flow velocity of $120 \mathrm{~cm} / \mathrm{s}$ to be an accurate predictor of clinically significant spasm. Transcranial Doppler has also been used to monitor hazardous procedures such as carotid endarterectomy giving warning of both hypoperfusion and hyperperfusion. Hypoperfusion may occur due to the effects of anaesthetic agents on the heart and on the autoregulation mechanism of the cerebral vessels. Hyperfusion is an unusual complication of endarterectomy but is thought to be due to a reduction in peripheral resistance of the cerebral circulation. Recently TCD has shown that emboli from the heart occur asymptomatically in patients with cerebrovascular disease. ${ }^{38}$

We have used TCD to monitor the progress of acute stroke and found that spontaneous reperfusion during the first week after a stroke does not result in the predicted oedema or an obviously increased tendency to haemorrhagic transformation, but leads to the converse and a reduced infarct size. ${ }^{39}$

Research with primate models in the 1970 s indicated that middle cerebral artery reperfusion after 90 minutes resulted in profound reperfusion oedema and haemorrhage. ${ }^{40} \mathrm{But}$ our own results indicate that reperfusion in patients leads to less oedema and smaller infarct size suggesting that the animal model, which involved ligation of the middle cerebral artery, does not correspond to the effect of thrombus lodging in the middle cerebral artery. (There is some evidence that build up of toxins such as nitrous oxide causes vasodilation and hence some reperfusion on a cyclical basis.) As thrombolysis becomes a more widespread treatment in stroke, TCD should be a valuable tool with which to monitor the success of treatment.

DUS IN OTHER VASCULAR DISEASE

Ultrasound has only a few "windows" in the skull to interrogate the cerebral arteries and visualisation of walls of small arteries is difficult.

It is not therefore an ideal method for studying diffuse disease such as vasculitis or fibromuscular hyperplasia, although the increased peripheral resistance will be reflected in the Doppler wave form. Arterial dissections are said to cause a backward and forward motion of blood in the internal carotid artery but we have found this sign unreliable; occurring also in acute middle cerebral artery occlusion.

Magnetic resonance angiography (MRA) Few techniques have developed as quickly as 
MRA. ${ }^{41}$ The first description of flow imaging was in 1985 by Wedeen et al. ${ }^{42}$ The details of time of flight (TOF) angiography ${ }^{43}$ and phase contrast MRA followed soon afterwards. ${ }^{44}$

\section{TECHNIQUE}

Blood can be imaged in two different ways by MRI; either as a negative signal (black blood) or as a positive signal (white blood). ${ }^{45}$

\section{BLACK BLOOD}

In conventional spin echo MRI, the pulse sequence consists of a $90^{\circ}$ radiofrequency pulse to magnetise the slice and a $180^{\circ}$ pulse, which rephases the exited protons before read out.

If blood flows out of the section being imaged in the time between these two radiofrequency pulses then a signal void occurs as there are no protons remaining for read out which then appears black on MRI. This phenomenon of a "flow void" can be magnified by using a presaturation band just outside the plane of interest. This reduces the alignment of protons along the $Z$ axis (the direction of the main magnetic field) and thus reduces the availability of inflowing protons to produce a signal in response to the radiofrequency pulse. Clearly, using a thin section technique and long repetition time will increase the likelihood of blood protons leaving the slice before refocusing, ${ }^{45}$ increasing the black blood effect. A long repetition time also increases the effect by increasing the signal from stationary tissues.

\section{WHITE BLOOD}

For positive signal imaging of the extracranial vessels the reverse principle is applied. The protons within the stationary tissues are saturated and the strong signal (white) comes from inflowing blood. For imaging white blood, two techniques have evolved-namely, TOF and phase contrast MRA.

\section{TIME OF FLIGHT ANGIOGRAPHY}

Time of flight angiography relies on rapid pulse sequences being applied to the area of interest so that the stationary tissues become saturated and only a few protons remain aligned along the main magnetic field and thus available to emit a signal.

Gradient echo pulse sequences are used that have a short repetition time $(30-60 \mathrm{~ms})$ and a small flip angle $\left(30-60^{\circ}\right) .^{46}$ If the repetition time becomes too short or if the flip angle is too large inflowing blood will also become saturated. A balance obviously has to be achieved because if the repetition time is increased too much not only will the saturation of blood be reduced but also that of the stationary tissues. The precise values used will depend on whether the blood is flowing across or in the plane of imaging. If the blood is flowing in plane the repetition time can be longer and the flip angle smaller. Imaging by TOF can be performed as a three dimensional volume slab or as a two dimensional technique whereby multiple thin sections are acquired; the second is more suitable for slow flow situ- ations as blood is less likely to become saturated as it travels through a thin slice. These MRA techniques have recently been reviewed by Edelman. ${ }^{46}$

\section{PHASE CONTRAST ANGIOGRAPHY}

Phase contrast relies on the principle that inflowing blood causes a shift in phase of the MR signal.

Two images have to be acquired; the first uses a positive gradient to induce positive flow related phase shifts whereas the second image has a negative gradient applied. The two images are then subtracted to remove the signal from background tissue. ${ }^{45}$ For coding in three directions at least six images are required. ${ }^{44}$

Saturation of inflowing blood does not occur and hence this technique is particularly suitable for slow flow situations such as that in veins, but it is time consuming.

\section{MAXIMUM INTENSITY PROJECTION (MIP)}

Raw data from these studies are projected into a three dimensional format by an elegant technique that stores the brightest signals from the data, which are then back projected as a two dimensional image. This maximum intensity projection can be tailored to the anatomy of interest, excluding veins and unwanted arteries. ${ }^{47}$ The data can then be rotated in three dimensions to obtain the optimal view of the pathology.

\section{RECENT DEVELOPMENTS}

Magnetic resonance angiography has been steadily refined and some of the recent developments include using magnetisation transfer to increase the saturation of the stationary tissue. ${ }^{4849}$ Magnetic resonance angiography involves the mobile protons; the restricted protons held by large molecules such as proteins are usually not visible, on account of their ultrashort T2 relaxation time. But these restricted protons can be energised by a powerful off resonance radiofrequency pulse as they have a wide range of resonant frequencies.

The magnetisation imparted to this restricted pool of protons will then be transferred to the mobile protons in the stationary tissue helping to cancel out its signal. Flowing blood has very few restricted protons and hence overall flow contrast is enhanced. Other techniques have evolved to improve the signal and reduce the saturation effects that occur in three dimensional TOF. These include tilted optimised non-saturating excitation (TONE), a technique that increases the flip angle as blood passes through the slice. This increases the signal from the flowing blood at a time when it is losing signal from saturation effects.

Travelling saturation bands may also be used; these are excited just before the arrival of blood and help to suppress the background signal. Sharper images have also been obtained by diastolic acquisition of images. ${ }^{50}$ Cerebral blood flow can now be quantified by exciting a bolus that is then tracked along the blood vessels. ${ }^{51} \mathrm{~A}$ similar technique of pre- 
saturation of the flow in a blood vessel can be employed for assessment of the collateral circulation to the territory supplied by the suppressed vessel. ${ }^{52}$

Uses of magnetic resonance angiography ARTERIOSCLEROTIC DISEASE: TECHNIQUE

Some centres use a three dimensional TOF technique for imaging carotid arteries that is less affected by turbulence and in which diameter measurements correlate better with conventional angiography. When there is a very tight stenosis, however, flow rates through the stenosis start to fall and occlusions may be falsely diagnosed. On account of this we have used both a three dimensional and a two dimensional technique. The thin slices of two dimensional TOF are much less likely to result in saturation than the thicker slabs of the volume three dimensional TOF method. ${ }^{53.56}$ The additional inspection of the individual images further reduces the chance of calling a tight stenosis an occlusion..$^{4654}$

\section{Results}

Several centres have already produced encouraging results using MRA as a screening test for carotid arteriosclerosis. Masaryk et al obtained an $R$ value of 0.94 when correlating a three dimensional TOF technique with conventional $x$ ray angiography. ${ }^{54}$ For a screening test high sensitivity is important, particularly if the consequences of missing the diagnosis can be devastating for the patient.

Sensitivities higher than colour flow DUS have been obtained in some hands $s^{586061}$ although this experience is not universal..$^{59} \mathrm{~A}$ recent prospective blinded trial of a few patients found that the accuracy of MRA equalled that of DUS. ${ }^{27}$ The most encouraging aspect of this series was that MRA correctly identified all the angiographic occlusions. Severe stenosis will cause variable lengths of complete loss of signal due to phase dispersal within the repetition time. This flow void has been found to be a sensitive $(0 \cdot 85)$ indicator of severe (70\%) stenosis. ${ }^{26}$ Ackerman and $\mathrm{Candia}^{28}$ have pointed out, however, that others have found a $25 \%$ false positive rate for this sign and that flow voids have been seen with stenoses of only $55 \% .^{26}$ They argue against the increasing practice of using an MRA flow void as an indication for surgery with no $x$ ray angiographic confirmation. This leads us back to the question of measurement. If it is a $55 \%$ NASCET measurement-that is, the least stenosis that leads to a flow voidthen ECST has shown that it is logical to offer surgery to these patients in any case.

The use of MRA in the diagnosis of carotid stenosis has many traps for the unwary; MRA may overestimate the length of stenosis. ${ }^{62}$ If blood forms pools in an ulcer saturation effects can occur. ${ }^{63}$ There are also artefacts from the maximum intensity projection algorithm, the background signal from the stationary tissue may become indistinguishable from the saturated slow flow that occurs along the arterial wall. ${ }^{62}$ Then there are the potential problems for MRA from intraplaque haemorrhage ${ }^{64}$ or intraplaque lipid which may give rise to bright signal despite the short repetition time. This causes T1 breakthrough from the background as this bright signal may prove indistinguishable from inflowing blood for the algorithm. It is important therefore to check the individual thin slices when assessing a stenosis as well as in suspected occlusion. ${ }^{64}$

In an experimental situation Podolak et al ${ }^{65}$ have shown that especially in two dimensional angiography there are not only phase encoding errors but, on account of the time delay between the radiofrequency pulse and frequency encoding. The flow can displace the signal leading to exaggeration of the stenosis. This has led researchers to try to find a conversion factor, but unfortunately the overestimation of stenosis is a non-linear function. ${ }^{66}$

Magnetic resonance angiography has the same problem as DUS in that it uses flow data to infer an anatomical abnormality. But the similarity of the images with angiography is deceptive and has lured some surgeons into operating without further studies. Masaryk and Obuchawski have emphasised that current announcements concerning the demise of angiography are somewhat premature. ${ }^{12}$

\section{ANEURYSMS AND ARTERIOVENOUS} MALFORMATIONS

Magnetic resonance angiography has become increasingly useful for detecting aneurysms. Ross et $a l^{67}$ reported a $95 \%$ accuracy for MRA when compared with conventional angiography. Only aneurysms of $5 \mathrm{~mm}$ diameter or less were missed and it has been claimed that the complication rate for these aneurysms is small; this seems to be the case with unruptured aneurysms, ${ }^{68}$ but it is not everyone's experience with aneurysms that have previously ruptured. ${ }^{69}$ Although not yet suitable for routine use in patients with subarachnoid haemorrhage there is possibly a role for MRA in those patients with negative $x$ ray angiography. Aneurysms may not be recognised on conventional angiography because of overlapping, tortuous vessels, or if they contain thromboses at the time of angiography. It is also suggested that spasm surrounding vessels may render aneurysms difficult to see, but this is debatable. Magnetic resonance angiography has been reported as positive after conventional angiography failed to show an aneurysm. ${ }^{70}$

There is certainly a role for MRA in elderly patients presenting with 3rd nerve palsy. These aneurysms are nearly always larger than $5 \mathrm{~mm}$. Computed tomography has also been successfully used for this purpose and the choice of technique will depend on local availability. ${ }^{71}$ We also currently use it as a screening test for aneurysms in patients with a strong family history of subarachnoid haemorrhage, while explaining to these patients the limitations of this technique to detect small aneurysms. Finally, MRA may find a role in following up aneurysms that have been treated by platinum coiling in which a residual neck is suspected. 
It should be stressed that MRA is not suitable for following up aneurysms that have been surgically clipped. Not only are there large artefacts from the metals used in patients who have had an aneurysm clipped but a death has occurred because of magnetic deflection of an aneurysm clip. Unfortunately the information available at the time of scanning concerning the clip was incorrect. If a patient with aneurysm clips has to be scanned, it has been recommended that the operation note is checked to make sure that the clip is of a type which is not ferromagnetic. Clips can even vary from batch to batch and the most recent recommendation is that all clips should be magnet tested before use. Arteriovenous malformations are clearly seen on MRI as well as MRA. ${ }^{72}$ The size of the nidus can be assessed and used to follow up the effect of radiosurgery or embolisation treatment; MRA does not, however, give sufficient data on feeding vessels and venous drainage for treatment decisions to be made. ${ }^{7374}$

\section{OTHER VASCULAR LESIONS: VASCULITIS, DISSECTION, AND FIBROMUSCULAR HYPERPLASIA}

Magnetic resonance angiography is not an ideal technique for imaging vasculitis. A recent study ${ }^{75}$ of a few cases with MRI showed a reasonable correlation with angiography, but MRA was not used in this study; MRA is not the modality of choice because not only is there the potential pitfall of false positive diagnosis (the distal arteries may appear beaded due to slow flow from other causes such as venous thrombosis), but also vasculitis may involve arteries smaller than the current resolution of MRA. Arterial dissection is better shown on angiography although successful diagnosis has been made by MRI. ${ }^{7677}$ The associated thrombus may have a brighter signal than the adjacent flowing blood ${ }^{64}$ confusing the maximum intensity projection algorithm. Fibromuscular hyperplasia is more likely to be a false positive diagnosis with MRA than a true one; the use of multiple thin slabs in two dimensional techniques ${ }^{78}$ does not always align due to movement and gives rise to a "venetian blind" artefact not unlike fibromuscular dysplasia. As this condition is also associated with cerebral aneurysms, angiography is the more suitable technique.

\section{MAGNETIC RESONANCE VENOGRAPHY}

Some tests do not have to go through the full validation process; their clinical value is immediately recognised. ${ }^{80}$ Magnetic resonance venography, particularly if venous thrombosis is suspected, falls into this category and in our department has already supplanted conventional venography. The same principles as those for MRA are used except that the saturation band is now placed to nullify inflowing arterial blood. A full understanding of MRA techniques is required as flow voids will occur when the slow venous flow remains in plane for any length of time, this commonly occurs in the transverse sinus near the torcular. ${ }^{8182}$ Reference to the individual T1 images is useful as thrombus will often give rise to a very bright signal and will confirm that a flow void is due to a clot. ${ }^{8384}$ Venous thrombosis may also give rise to parenchymal haemorrhage, infarcts, hydrocephalus, and dilatation of the deep periventricular veins. Some tumours, particularly meningiomas, encroach on the deep veins. This information is valuable to the surgeon as complete occlusion of the vein allows it to be sacrificed without danger.

The smaller veins may be better visualised by introduction of gadolinium which will also allow the circulation of some tumours to be seen on MRA. ${ }^{85}$

\section{COMBINED DUS AND MRA FOR SCREENING THE} CAROTID

Recently several authors have suggested that a combination of these two tests may replace angiography for arteriosclerotic disease. ${ }^{27} 29628687$ This combination of tests is attractive as DUS is very sensitive for detecting stenoses up to $50 \%$ and MRA, and, particularly if a technique sensitive to low flow is selected, can often be used to distinguish between complete occlusion and very tight stenoses. The published data are as yet few, but Polak has already claimed that this combination of tests would result in a $99 \%$ sensitivity for detecting surgical cases. This claim is made on the basis that both tests have about $90 \%$ sensitivity; therefore, theoretically both tests combined will produce only one false positive result in $100 .^{8}$ This, however, makes the large assumption that the tests are completely independent, whereas we know that both tests have difficulties in the same pathological situations - for example, patients with complete or near complete occlusion and those with tortuous arteries. Masaryk and Obuchawski have criticised Polak's data on several counts, but mainly on the lack of any independent reference investigation-for example, $x$ ray angiography-for some of the patients in their paper. ${ }^{12}$

A recent study from Liverpool ${ }^{87}$ overcomes many of the methodological objectives that have been made to the studies already mentioned. These workers compared prospectively DUS and MRA with $x$ ray angiography (DSA). They avoided the error of using correlation coefficients in the analysis of their results and report the agreement of their tests at every degree of percentage stenosis $(0-100 \%)$. This is valuable for the future as we are still uncertain at what percentage stenosis surgery becomes the appropriate treatment. In their hands, if DUS and MRA agreed then $6 \%$ of patients were misclassified when compared with DSA and they make the reasonable point that this degree of inaccuracy is offset by the absence of risk of DUS and MRA when compared with invasive radiology. Unfortunately there are few hospitals with such an experienced ultrasonographer. So, the jury is still out, although early results are encouraging. 
COMPUTED TOMOGRAPHY

The advent of spiral CT ${ }^{88}$ has meant that the cervical carotid artery can be scanned in under 30 seconds. Scan data are acquired continually as the patient moves through the scanner during an infusion of contrast medium. ${ }^{89}$ Data processing currently takes longer, up to 10 minutes, and uses either the same image projection (maximum intensity projection) methods as in MRA or one of the other three dimensional display techniques that have been developed specifically for CT. Early results have been impressive. A study by Marks et al of a group of 28 patients found a good correlation when CT was compared blind with angiography, with $89 \%$ of cases falling into the same three categories $(0-30$, $30-70,70-100 \%)$ of narrowing. ${ }^{61}$ Computed tomography has a very high sensitivity to contrast and both cases of occlusion were correctly identified. This may turn out to be one of the major advantages of the technique.

There are, however, also problems related to $\mathrm{CT}$; scanning protocols typically include only a small segment, usually $6 \mathrm{~cm}$, of the cervical carotid artery and lesions outside this small window will be missed.

Calcified lesions, if dense, will cause beam hardening and increase the apparent narrowing of the vessel lumen, particularly if the calcification is circumferential. Conversely, if the calcification is faint there is potential for a partial volume artefact and part of the density of the vessel wall being falsely interpreted as contrast medium. (The ability to show the degree of calcification may also be helpful in the selection of patients for angioplasty.) There are other advantages over MRA as currently performed in that the superior resolution of the CT images allows for cross sectional measurements to be made. The physiological effect of circumferential and asymmetric lesions is very different. Finally, angiographic ulceration has been shown to be an important risk factor in severe stenosis ${ }^{29}$ but MRA is a relatively poor technique for demonstrating ulceration; CT may prove to be more sensitive for detecting ulcers.

In summary, CT has potential advantages as a technique for assessing carotid stenosis. It has the advantage over DUS and MRA that it can give a diameter measurement of carotid stenosis and does not rely on a physiological measurement. It is therefore more likely on theoretical grounds to be able to select patients that will benefit from surgery. But until these advantages become clear cut with larger series it is unlikely to win widespread acceptance on account of the high $x$ ray dose and the requirement for an intravenous contrast agent.

\section{Angiography}

The modern era of angiography started with Seldinger ${ }^{90}$ who in 1953 described his percutaneous technique with admirable brevity as "needle in, wire in, needle out, catheter over wire, wire out, that is all". Since that time, developments in technology have resulted in smaller softer tipped catheters that cause less trauma to the arterial wall, contrast agents that are less toxic, and improved $x$ ray equipment, particularly of high resolution digital substraction angiography (DSA) which has meant that carotid angiography can be performed very quickly (15-20 minutes).

\section{ANGIOGRAPHY FOR ARTERIOSCLEROTIC}

\section{DISEASE: TECHNIQUE}

Angiographic techniques must be meticulous and not left in the unsupervised hands of junior staff, when the risks can be three times as high. ${ }^{91}$

Short examination times, small soft catheters, the use of safety $J$ guidewires that are kept below the carotid bifurcation, nonionic contrast agents, and DSA all probably reduce the risks.

We routinely perform a lateral and two oblique views as it has been shown that if two views only are used $40 \%$ of lesions are missed. ${ }^{92}$ Some modern angiographic equipment can "spin" through $90^{\circ}$ or $180^{\circ}$ during a single slow injection and thus the projection revealing maximum stenosis can be selected for measurement. It is possible to include the carotid siphon and intracranial carotid vessels on a single image with even small image intensification systems (9 inches) reducing examination time.

\section{ADVANTAGES OF ANGIOGRAPHY}

The advantages of angiography are that it is an established technique with proved ability to select patients who will benefit from carotid endarterectomy. It is a high resolution technique with high agreement between observers. ${ }^{93}$ It can demonstrate not only the carotid bifurcation region but also the carotid origin, carotid siphon, and distal branches. Proximal stenosis at the origin of the common carotid artery is rare $(1 \cdot 5 \%-5 \%),{ }^{94}$ so that many centres do not routinely perform arch aortography, particularly as proximal stenosis is seldom sufficiently severe to influence surgical decisions. Moseley has claimed that a case in which the common carotid artery was occluded would be the "case of the year" in his department. ${ }^{95}$ Distal internal carotid disease, particularly involving the carotid siphon, may have a more sinister implication ${ }^{969}$ and the incidence of "tandem stenosis" has probably been underestimated and $15 \%$ of those carefully investigated by angiography in a recent trial had significant intracranial carotid artery stenosis. ${ }^{32}$ The plaque itself can be assessed not only in terms of width and length but also for ulceration, which has recently been shown to be a risk factor for stroke. ${ }^{29}$

\section{RISKS OF ANGIOGRAPHY}

Before subjecting any patient to angiography it is important to try to ensure that the benefits outweigh the risks. Studies showing that the risks of angiography are markedly increased in the hands of the inexperienced support the view that most of the complications result from trauma to the wall of the vessel and clots forming either on the vessel wall or on the 
catheter during the procedure. Transcranial Doppler has recently been used to show that multiple emboli pass into the middle cerebral artery during angiography. ${ }^{98}$ We reviewed the results of eight retrospective and seven prospective trials that assessed angiographic complications in patients with mild cerebrovascular disease and concluded that the overall permanent neurological complication rate was $1 \%$ in patients with symptomatic cerebrovascular disease. ${ }^{91}$ Since these studies were performed, new catheter designs and DSA have led to reports of much lower complication rates. Grzyska et al reviewed the complications of angiography in 1095 patients and established a permanent complication rate of $0.09 \%,{ }^{99}$ but these patients were not preselected by ultrasound and only $30 \%$ of the angiograms were performed for cerebrovascular disease. Waugh and Sacharias reported even better results with only $0.03 \%$ of patients having permanent neurological disability. ${ }^{100}$ Very low complication rates of angiography in patients with symptomatic cerebrovascular disease should be regarded with suspicion. The natural history of patients with transient ischaemic attacks is a $4 \cdot 4 \%$ (or higher) risk of a stroke in the first month after the presenting event. ${ }^{107}$ This means that the expected stroke rate in these patients during the 72 hours after angiography will be at least $0.5 \%$ and if preselected by carotid ultrasound, possibly as high as $1 \%$. The effect of screening patients with DUS has resulted in only patients with more severe degrees of atheromatous disease having angiography and thus in some other centres increasing risks of angiography have been reported. A recent prospective study found a $4 \%$ permanent neurological complication rate from angiography. ${ }^{101}$ These complications were during a 72 hour period after angiography and some are likely to be unrelated to the procedure in these patients at risk. ${ }^{102}$ Unfortunately there is likely to be publication bias in these studies. Centres with a high complication rate are unlikely to publish their results in a competitive market unless they are keen to abandon angiography! I suspect that the complication rate remains at around $1 \%$ in most centres with the advantages of improved technology being cancelled out by preselection of more severely diseased patients by DUS.

The neurological complications of angiography may be reduced by using intravenous DSA. Good results in some hands have been achieved with acceptable images in $80 \%$ of patients. ${ }^{103104}$ Inadequate contrast due to poor left ventricular function, or artefact from patient swallowing during the procedure combined with poor overall resolution of the images have, however, prevented its widespread acceptance. The reasons for this failure have been reviewed by Cebul and Paulus. ${ }^{105}$ There has been a surprisingly high systemic complication rate reported by some authors. Turner et al found a $9 \cdot 1 \%$ incidence of myocardial ischaemia and pulmonary oedema. ${ }^{106}$ The improving technology of DSA has resulted in intravenous DSA achieving more acceptable, higher resolution images, and of a resurgence of interest in the technique.

\section{Aneurysms}

Angiography is the investigation of choice in acute subarachnoid haemorrhage. Routinely, we perform angiography of both carotid arteries and the dominant vertebral artery.

Three views are taken of each carotid: anteroposterior, lateral, and oblique. If no aneurysm is demonstrated then further views may be indicated with the purpose of opening out vessel loops. ${ }^{108}$ These further views are focused by the apparent source of bleeding shown by CT. If a single vertebral artery injection does not opacify both posterior inferior cerebellar arteries, bilateral vertebral angiography is performed. Occasionally a more limited protocol is used-for example, in elderly patients in whom a posterior circulation aneurysm would be treated conservatively the vertebral angiogram may not be performed, or in patients who have large deep hemispheric bleeds in whom the purpose of angiography is to exclude an underlying vascular abnormality on the side of the bleed. In such circumstances a single carotid angiogram is often obtained.

Information on the patency of the circle of Willis can be important to the surgeon. The anterior communicating artery may need to be preserved if both anterior cerebral arteries fill from one carotid artery and the other anterior cerebral artery is hypoplastic. Cross compression studies are sometimes. performed to distinguish between hypoplastic and absent Al segments.

In $75 \%-85 \%$ of patients with acute subarachnoid haemorrhage, an underlying aneurysm, or vascular malformation will be shown. The cause of failure of initial angiography is often uncertain but may be due to thrombosis, spasm, misinterpretation of tortuous vessel loops, or a perimesencephalic bleed that may not be aneursymal in origin. ${ }^{70}$ Repeat angiography is of debatable value with some series having only a $2 \%$ detection rate of aneurysms and Moseley has argued that the risks of repeat angiography often outweigh the benefits. ${ }^{110}$ Our own experience is of a higher incidence of detecting aneurysms by repeating angiography. This is possibly due to a policy of performing angiography early on often uncooperative patients, but Wolpert and Caplan have reported results similar to our own, finding aneurysms in $5 \%$ of repeated studies. ${ }^{11}$

Because the risks of angiography in this group of patients is small, ${ }^{112}$ we do perform repeat angiograms at four weeks or when the spasm has resolved (on transcranial Doppler) on all patients unless the quantity of blood on CT is small and restricted to the perimesencephalic cisterns, the proximal interhemispheric, or sylvian fissures. Such a distribution indicates a perimesencephalic bleed and the yield of repeat angiograms on such patients with perimesencephalic blood is low. ${ }^{110}$ 
Multiple aneurysms are present in $10 \%-$ $30 \%$ of patients. ${ }^{11113}$ The correct management of the unruptured aneurysms is the subject of a current multicentre trial. At present our current policy is to operate on or coil unruptured aneurysms in young patients with aneurysms that are greater than $5 \mathrm{~mm}$. We are currently following small aneurysms with MRA, as the available evidence suggests that rupture of these aneurysms is rare. ${ }^{68}$

Angiography is an integral part of the treatment of aneurysms as well as diagnosis. Aneurysms can be treated angiographically in several ways.

All methods rely on preliminary angiography to assess the anatomy of the aneurysm, in particular the size, shape, and neck size. Subsequent treatment depends on the site and size. "Berry" aneurysms , found around the Circle of Willis and at the bifurcations of the main cerebral arteries can be treated by introducing platinium coils into the lumen or by balloons positioned either in the neck or within the sac of the aneurysm. ${ }^{114}$ The most recent development is to use coils, the detachment of which can be controlled. These coils, developed by Guglielmi et $a l^{115}$ are released by passing a small current down the mandril to the coil. This causes thrombosis within the aneurysm and then releases the coil by electrolysis of the solder between the coil and its steel mandril wire. Balloon placement within aneurysms is now less common and in many centres is restricted to parent vessel occlusion in the treatment of carotid aneurysms. Modern DSA equipment contributes significantly to the speed and safety with which these procedures can be carried out. The position of the embolic material can be rapidly assessed and any prolapse into the feeding arterial systems rectified. The road map facility enables the radiologist to visualise the arteries during superselective catheterisation and prevents the guide wires from passing through the aneurysm wall.

\section{Arteriovenous malformations}

Angiography is the only modality that demonstrates fully the vessel architecture of arteriovenous malformations. This information is essential for planning treatment, either by surgery, intra-arterial embolisation, or radiosurgery, each or all of which may have a role. The risks of surgery have been graded by Spetzler and Martin. ${ }^{116}$ Grading depends on the location, the size of the nidus, and whether the venous drainage is to the superficial or deep veins. Pre-embolisation assessment includes identification of the number of feeders, the venous drainage, any external carotid supply, and an estimate of the rate of flow. ${ }^{117}$ Lesions with multiple small tortuous feeders are usually difficult to embolise fully. Stereotactic radiosurgery on the other hand is most suited to lesions that are less than $3 \mathrm{~cm}$, with deep lesions typically responding better than peripheral lesions. No prospective trial has yet shown the superiority of any particular treatment and this will be difficult to design because a combined approach using two of these treatments is often required. Occasionally, thrombosis of an arteriovenous malformation will cause it to be missed on angiography but the presence of methaemoglobin and haemosiderin often enable visualisation by MRI. These thrombosed malformations do not require treatment. Small arteriovenous malformations that are compressed by a large haematoma in the acute phase can also be missed if angiography is performed early. In young non-hypertensive patients or with peripherally situated haematomas we repeat angiography when the mass effect has resolved, usually after two to four weeks.

\section{Other vascular lesions}

Cranial arteritis may be restricted to the cranial circulation or may be part of a collagen vascular disease such as systemic lupus erythematosus. Rarer causes include drug misuse, particularly with amphetamines, heroin and cocaine, and radiation. ${ }^{110}$ Arteries show evidence of narrowing and dilatation or "beading", which may be focal or widespread. Cranial arteritis involves the proximal vessels as do most of the drug induced vasculitides.

Systemic lupus erythematosus and polyarteritis attack the medium and small vessels, occasionally with the formation of small aneurysms. ${ }^{118}$ Radiation affects the very small arteries so that often no changes are noted on angiography, although in rare cases a larger vessel is involved. ${ }^{119}$ The contraceptive pill has been reported to result in not only venous but also arterial occlusions. ${ }^{11}$

Fibromuscular dysplasia is best recognised on angiography. ${ }^{120}$ The classic irregular narrowing of the carotid artery can be mimicked by pressure waves induced at the time of intra-arterial contrast injection but these waves can be distinguished by their regularity. This disease, which is commoner in females, can be associated with intracranial aneurysms.

Dissection of the carotid or vertebral arteries often follows direct neck trauma. In the absence of trauma, the patients sometimes give a history of sudden neck pain. The typical appearance is of a carotid artery which tapers gradually like a "rat's tail". ${ }^{121}$

It is rare to see an intimal flap or false lumen except when induced by angioplasty.

Marfan's disease and Ehlers-Danlos syndrome, in which the elastic fibres of the arterial media are inherently weak, are diseases associated with dissections and caroticocavernous fistulae. These are difficult to treat conventionally as the arteries are often further traumatised by balloon placement.

\section{VENOGRAPHY}

The main indication for venography is suspected venous obstruction due either to thrombosis or tumour. Venous thrombosis can be due to otitis media or mastoiditis, pregnancy or the pill, malignancy, and trauma.

Magnetic resonance venography (MRV) 
has to a large extent replaced conventional venography but when not available or if the MRV result is unsatisfactory, conventional venography is still performed. Meticulous technique is again required; bilateral catheterisation of the carotid arteries with simultaneous injection is recommended by Newton and Potts, ${ }^{122}$ but even then interpretation can be difficult. Abnormalities such as tumours adjacent to the sinuses can cause sufficient narrowing to mimic complete obstruction.

The central lumen of the vein may not opacify due to streaming of contrast along the vessel walls. Secondary features such as reversal of flow in the cortical veins and drainage into collateral pathways are useful signs to confirm the presence of obstruction.

\section{Costs}

The cost and the charge of examinations differs considerably around the world and even local costs are difficult to assess in the National Health Service (NHS) of the United Kingdom. ${ }^{123}$ The costs of an individual examination will depend on patient throughput in a unit, over how long a period equipment is written off and replaced, salary costs, etc. Our own costs are based on using modern equipment with a moderately high throughput of patients and writing off the equipment over an eight year period. The charges to patients referred from other centres are as follows:

\begin{tabular}{lrll}
\hline & $\begin{array}{l}\text { Cost/ } \\
\text { exam }\end{array}$ & Equipment & $\begin{array}{l}\text { Exams/ } \\
\text { year }\end{array}$ \\
\hline $\begin{array}{l}\text { Angiography } \\
\text { MR including }\end{array}$ & $£ 350$ & GE DX Highline & 1000 \\
$\begin{array}{c}\text { angiography } \\
\begin{array}{c}\text { Colour flow } \\
\text { ultrasound }\end{array}\end{array}$ & $£ 167$ & Siemens 1.5T 63SP & 5000 \\
\hline
\end{tabular}

In the new climate NHS these charges should approximate to costs (apart from an additional $10 \%$ administration fee). Angiography will often involve overnight hospital accommodation with a charge of $£ 200$ a night to be added to the costs. If patients can be spared angiography by using a screening test such as DUS, considerable cost savings can be made. ${ }^{123}$

\section{Summary}

ATHEROSCLEROTIC DISEASE

Patients with transient ischaemic attacks or a non-disabling stroke who are surgical candidates should be screened with Doppler ultrasound, or MRA/CT, or both. The choice will depend on local expertise and availability. If DUS is used it is recommended that the equipment is regularly calibrated and a prospective audit of results, particularly of those patients that go on to angiography, is maintained locally. Those patients found to have the DUS equivalent of a $50 \%$ stenosis should have angiography only if surgical or balloon angioplasty treatment is contemplated. Angiography should be performed with meticulous technique to minimise risks.
ANEURYSM AND ARTERIOVENOUS

MALFORMATIONS

Angiography remains the investigation of choice for patients with subarachnoid haemorrhage. Magnetic resonance angiography and CT can demonstrate the larger aneurysm but because even small aneurysms can rupture with devastating effects, these techniques are not the examination of first choice. Angiography is also the only technique that adequately defines the neck of an aneurysm.

This information is becoming increasingly important in management decisions-for instance, whether to clip or use a coil. Likewise angiography is the only technique to fully define the vascular anatomy of arteriovenous malformations although the size of the nidus can be monitored by MRA and this is a useful method of follow up after stereotactic radiosurgery, embolisation, or surgery. There are specific uses for MRA such as in patients presenting with a painful 3rd nerve palsy and as a screening test for those patients with a strong family history of aneurysms.

\section{VASCULITIS, FIBROMUSCULAR HYPERPLASIA,} AND DISSECTION

These rare arterial diseases are best detected by angiography, although there are increasing reports of successful diagnosis by MRA. There are traps for the many unwary and MRA does not give an anatomical depiction of the arteries but a flow map. Slow flow may lead to signal loss and a false positive diagnosis of vasculitis.

\section{Conclusion}

Imaging techniques for the cerebral blood vessels develop so rapidly that it is difficult to say with confidence what the status is at any one time. The pace of new developments leads to its own problems. When has a technique improved to the point that a proper prospective randomised controlled trial is indicated? Clinical outcome should be the gold standard against which tests should be measured. But studies using clinical outcome as the endpoint, such as NACSET, take 10 years to complete and by that time the technique has been superseded. Thus clinicians must often make do with small trials that may be retrospective and use a gold standard such as angiography, which itself has many disadvantages as a test. The analysis of such data to develop a sensible local policy will always remain a challenge.

"Errors in judgement must occur in the practice of an art which consists largely in balancing probabilities"

\section{Sir William Osler}

I thank Dr J Wardlaw and Dr I Marshall for their help with the manuscript.

\footnotetext{
1 Geddes LA, Geddes LE. The catheter introducers. Chicago: The Mobium Press, 1993:15.

2 Todd NV, Howie JE, Miller JD. Norman Dott's contribution to aneurysm surgery. I Neurol Neurosurg Psychiatry 1990;53:455-8.
} 
3 Eastcott HHG, Pickering GW, Robb C. Reconstruction of internal carotid artery in a patient with intermitten attacks of hemiplegia. Lancet 1954;ii:994-6.

4 North American Symptomatic Carotid Endarterectom Trial Collaborators. Beneficial effect of carotid endarterectomy in symptomatic patients with high grade carotid stenosis. N Engl f Med 1991;325:445-53.

5 European Carotid surgery trialists Collaborative Group. MRC European Carotid Surgery Trial: interim results for symptomatic patients with severe (70-99\%) or with mild (0-29\%) carotid stenosis. Lancet 1991;337: $1235-43$.

6 Rankin RN, Fox AJ, Thorpe K, et al for NASCET collaborators. Carotid ultrasound: correlation with angiography in a multicentre trial. Presented to the American Society of Neuroradiology, St Louis: 31 May-5 June, 1992

7 Spencer MP, Reid JM. Quantification of carotid stenosis with continuous wave doppler ultrasound. Stroke 1979; 10:226-330.

8 Polak JF. Noninvasive carotid evaluation. Carpe Diem Radiology 1993;186:329-31.

9 Rothwell PM, Gibson RT, Slattery J, Sellar RJ, Warlow $\mathrm{CP}$. Equivalence of measurement in carotid stenosis. A comparison of three methods on 101 angiograms. Stroke 1994;25:2435-9.

10 Bland M, Altman DEG. Statistical methods for assessing agreement between two methods of clinical measurement. Lancet 1986;i:307-10.

11 Howard G, Chambless LE, Baker WH, et al. A multicentre validation study of Doppler ultrasound versus centre validation study of Doppler ultrasound versu

12 Masaryk TJ, Obuchowski NA. Noninvasive carotid imaging caveat emptor. Radiology 1993;186:325-8.

13 Carroll BA. Carotid sonography. Radiology 1991;178 303-13.

14 Zweibel WJ. Duplex sonography of cerebral arteries: efficacy limitations and indications. AfR Am $\mathcal{f}$ Roentgenol 1992;158:29-36.

15 Huning MGM. Polak JF, Barlaw MM, O'Leary DH. Detection and quantification of carotid artery stenosis. Efficiency of various Doppler velocity parameters. $A F R$ Am $\mathcal{F}$ Roentgenol 1993;160:619-25.

16 Robinson ML, Sacks D, Perlmutter GS, Merinelli DC. Diagnostic criteria for carotid duplex - sonography. AfR Am F Roentgenol 1988;151:1045-9.

17 Roederer GO, Langlois YE, Jager KA. A simple spectral parameter for accurate classification of severe carotid disease. Bruit 1984;8:174-8.

18 Cardullo PA, Cutler BS, Brownwell-Wheeler L. Detection of carotid artery disease by duplex scanning. f Diag Med Sanog 1986;7:63-73.

19 Goodison SF, Flanigan P, Bishara P, Schuler JJ, Kikta MJ, Meyer JP. Can duplex scanning supplant arteriography in patients with focal carotid territory symptoms? F Vasc Surg 1987;5:551-7.

20 Hartwell GG. Controversies in radiology: Doppler of the carotid artery. Clin Radiol 1989;40:177-88.

21 Zweibel WJ, Austin CW, Sackett JF, Strother CM. Correlation of high-resolution, B-mode and continuous wave Doppler sonography with arteriography in the diagnosis of carotid stenosis. Radiology 1983;149: 523-32.

22 Clark WM, Hatten HP. Non-invasive screening of extracranial carotid disease: duplex sonography with angiographic correlation. AfNR Am 7 Neuroradiol 1981;2: 443-7.

23 Benedict PJ, Jackson WP, Becker GJ. Comparison of ultrasound scanning/Doppler with digital subtraction angiography in evaluating carotid arterial disease. Medical Instruments 1983;3:220-2.

24 Cardullo PA, Cuttler BS, Wheeler AB, Arous EJ, Hapmann JB. Accuracy of duplex sonographic scanning in the detection of carotid arterial disease Bruit ning in the de

25 Wetzner SM, Tutunjian J, Marich KW. Focus on duplex sonographic scanning: a vascular diagnostic technology. American Review of Diagnostics 1983;1:31-6.

26 Mittl RLJ, Broderick M, Carpenter JP, et al. Blindedreader comparison of magnetic resonance angiography and duplex ultrasonography for carotid artery bifurcation stenosis. Stroke 1994;25:4-10.

27 Houston J III, Lewis BD, Weibers DO, Meyer FB, Reiderer SJ, Weaver AL. Carotid artery: prospective blinded comparison of two dimensional time of flight MR angiography with conventional angiography and duplex US. Radiology 1993;186:339-44.

28 Ackerman RH, Candia MR. Identifying clinically relevant carotid disease. Stroke 1994;25:1-3.

29 Eliasziw M, Streiflet JY, Fox AJ, Hachinski VC, Ferguson GG, Barnett JHM. Significance of plaque ulceratation in symptomatic patients with high grade carotid stenosis. Stroke 1994;25:304-8.

30 O'Leary DH, Polak JF. High resolution carotid sonography; past present and future. AfR Am F Roentgenol 1989;153:699-704

31 Zweibel WJ, Crummy AB. Sources of error in Doppler diagnosis of carotid occlusive disease. $A \mathscr{F} R A m$ Roentgenol 1981;2:231-42.

32 Griffiths PD, Worthy S, Gholkar A. Incidence of vascular pathology in patients investigated for carotid stenosis. Neuroradiology 1995 (in press)

33 Little JR, Sawhny B, Weinstein M. Pseudo tandem lesions of the internal carotid artery. Neurosurgery 1980; 15:574-77.
34 Stepetti AV, Schultz D, Feldhans RT, et al. Ultrasonographic features of carotid plaque and risks of subsequent neurological deficits [abstract]. Radiology 1989; 171:883

35 Wolverson MF, Bashiti HM, Peterson GJ. Ultrasonic classification of alteromatous plaques using a high resolution real time scanner. Ultrasound Med Biol 1983;

36 Imparto AM, Riles TS, Mintzer K, et al. The importance of haemorrhage in the relationship between gross morphologic characteristics and cerebral symptoms in 376 carotid artery plaques. Ann Surg 1983;197:195-8

37 Norris JW. Does transcranial doppler have any clinical value? Neurology 1990;40:329-31.

38 Grosset PG, Georgiaris MD, Abdullah MD, Lees KR Doppler Emboli Signals vary according to stroke subtype. Stroke 1994;25:382-4

39 Wardlaw JM, Dennis MS, Lindley RI, Warlow CP, Sandercock PAG, Sellar RJ. Does early reperfusion of a cerebral infarct influence cerebral infarct swelling in the acute stage or the final clinical outcome? Cerebrovascular Diseases 1993;3:86-93.

40 Symon L. Experimental cerebral infarction. Progress in stroke research. Bath: Pitman Medical, 1979:79-93.

41 Crosby DC, Turski PA, Davis WC. Magnetic resonance angiography and stroke; techniques, applications and
limitations. Neuroimaging Clinics of North America 1992; 2:509-31.

42 Wedeen V, Meuci R, Edelman RR, et al. Projective imaging of pulsatile flow with magnetic resonance. Science 1985;230:946-8

43 Haase A, Frahm J, Matthaei D, Hanicke W, Merbolt KD. FLASH imaging: rapid NMR imaging using low flip angle pulses. $\mathcal{F}$ Magn Reson Imaging 1986;67: 256-66.

44 Dumoulin C, Souza S, Walker M, Wagle W. Threedimensional phase contrast angiography. Magn Reson Med 1989;9:139-49.

45 Edelman RR, Mattle HP, Wallner B, et al. Extracranial arteries; evaluation with "black blood" MR angiography. Radiology 1990;177:45-50.

46 Edelman RR. MR angiography: present and future. $A F R$ Am f Roentgenol 1993;161:1-11.

47 Baker MC, Kucharczyk J, Sevick RJ, Mintorovitch J, Moseley ME. Recent advances in the MR imaging/ spectroscopy of cerebral ischemia. $A \mathcal{F} R A m \mathcal{F}$ Roentgenol 1991;156:1133-44.

48 Wolff SC, Balaban RS. Magnetisation transfer contrast (MTC) and tissue water proton relaxation in vivo. Magn Reson Med 1988;10:135-44.

49 Edelman RR, Ahn S, Chien D, et al. Improved time of flight MR angiography of the brain using magnetisation transfer contrast. Radiology 1992;184:395-9.

50 Saloner D, Salby K, Anderson CM. MRA Studies of arterial stenosis. Improvements by diastolic acquisition. Magn Reson Med 1994;31:196-203.

51 Edelman RR Mattle HP, Kleefield J, Silver MS. Quantification of blood flow with dynamic MR imaging and presaturation bolus tracking. Radiology 1989;171:

52 Edelman RR, Mattle HP, O'Reilly GV, Wentz KV, Liv C, Zhao B. Magnetic resonance imaging of flow dynamics of the circle of Willis. Stroke 1990;21:56-65.

53 Lasster RE Jnr, Acker JD, Halford HH, II, Nauert TC Assessment of $M R$ angiography versus arteriography for evaluation of cervical carotid bifuracation disease. AfNR Am $\mathcal{f}$ Neuroradiol 1993;14:681-8.

54 Masaryk AM, Ross JS, DiCello MC, Modic MT, Paranadi L, Masaryk TJ. 3DFT MR angiography of the carotid bifurcation. Potential and limitations of the screening examination. Radiology 1991;179:797-804.

55 Lewin JS, Laub G. Intracranial MR Angiography: a direct comparison of 3 time of flight techniques. $A \mathcal{F} N R$ Am $\mathcal{F}$ Neuroradiol 1991;12:1133-9.

56 Keller PJ, Drayer BP, Fram EK, Williams KD, Dimoulin CC, Souza SR. MR angiography with two-dimensiona acquisition and three dimensional display. Radiolog 1989;173:527-32.

57 Anderson CM, Saloner D. Leere, et al. Assessment of carotid artery stenosis by $\mathrm{MR}$ angiography; comparison with $\mathrm{X}$-ray angiography and colour-coded Doppler ultrasound. AfNR Am ₹ Neuroradiol 1992;13: 989-1003.

58 Mattle HP, Kent KC, Edelman RR, Atkinson DJ, Skillman JJ. Evaluation of the extracranial carotid: correlation of magnetic resonance angiography, duplex ultra sonography and conventional angiography. 7 Vasc ultra sonography and

59 Polak JF, Bajakian RC, O'Leary DH, Anderson MR Donaldson MC, Jolesz FA. Detection of interna carotid stenosis comparison of MR angiography, colou Doppler sonography and arteriography. Radiology 1992;182:35-40.

60 Heirserman JE, Draper BP, Fram EK, et al. Carotid artery stenosis: clinical efficacy of two dimensional tim of flight MR angiography. Radiology 1992;182:761-8.

61 Marks MP, Napel S, Jordan TE, Enzmann DR. Diagnosis of carotid artery disease: preliminary experience with maximum-intensity projection Spiral CT angiography. AfR Am $\mathcal{f}$ Roentgenol 1993;160:1267-71.

62 Laub G. Displays for MR angiography. Magn Reson Med 1990;14:222-9.

63 Anderson CM, Saloner D, Tsuruda JA, Shapeero LG, Lee RE. Artifacts in maximum-intensity projection display of MR angiograms. $A \Im R A m \Im$ Roentgenol 1990 ; play of MR 
64 Yousem DM, Balakrishnan, Debrun GM, Bryan RN. Hyperintense thrombus on GRASS MR images: potential pitfall in flow evaluation. AfNR Am $\mathcal{F}$ Neuroradiol 1990;11:51-8.

65 Podolak MJ, Hedlund LW, Evans AJ, Herfkens RJ. Evaluation of flow through simulated vascular stenosis with gradient echo magnetic resonance imaging. Invest Radiol 1989;24:184-9.

66 Sitzer M, Furst G, Fischer H, Siebler M, Fehlings T, Kleinschmidt A, et al. Between-method correlation in quantifying internal carotid stenosis. Stroke 1993;24: 1513-8.

67 Ross JS, Masaryk TJ, Modic MT, Ruggier PM, Haacke EM, Selman WK. Intra cranial aneurysms: evaluation by MR angiography. AfR Am $\mathcal{f}$ Roentgenol 1990;155: $159-65$.

68 Wiebers DO, Whisnant JP, Sundt TM, O'Fallon WM. The significance of unruptured intracranial saccular aneursysms. F Neurosurg 1987;66:23-9.

69 Weir B. Aneurysms affecting the nervous system. Baltimore: Williams and Williams, 1987:303-63.

70 Curness T, Shogry ME, Clark DC, Elsner JH. MR Angiographic demonstration of intracranial aneurysm
not seen on conventional angiography. $A \mathcal{F} N R A m \mathcal{F}$ Neuroradiol 1993;14:974-7.

71 Teasdale E, Statham P, Straiton J, Macpherson P. Non-invasive radiological investigation for oculo 549-53.

72 Potchen ET, Haacke EM, Siebert JE, Cottschalk A. Magnetic resonance angiography: concepts and applications. Mosby, 1993:394.

73 Houston J, III, Rufenacht DA, Ehman RL, Weibers DO. Intracranial aneurysms and vascular malformations: comparison of time of flight and phase contrast MR angiography. Radiology 1991;181:721-30.

74 Marchal G, Bosmans H, Van Fraeyenhoven L, et al. Intracranial vascular lesions: optimation and clinical evaluation of three-dimensional time of flight angiography. Radiology 1990;175:443-8.

75 Greenan TJ, Grossman RI, Goldberg HI. Cerebral vasculitis: MR imaging and angiographic correlation. Radiology 1992;182:65-72.

76 Goldbert HI, Grossman RI, Comori JM, Ashburh AK, Bilaniuk LT, Zimmerman KA. Cervical internal carotid artery dissecting haemorrhage: diagnosis using MR. Radiology 1986;158:157-61.

77 Quint D, Spickler E. Magnetic resonance demonstration of vertebral artery dissection; report of two cases. f Neurosurg 1990;72:964-7.

78 Heiserman JE, Drayer BP, Fram EK, Keller PJ. MR angiography of cervical fibromuscular hyperplasia. AfNR Am ₹ Neuroradiol 1992;13:1454-7.

79 Blatter DD, Parker DC, Robinson RO. Cerebral MR angiography with multiple overlapping thin slab acquisition: Part II Early clinical experience. Radiology 1992; 183:379-89.

80 Perlmutter JS. New techniques in neuroimaging: When are pretty pictures useful? Current Opinion in Neurology 1993;6:889-90.

81 Rippe DJ, Boyko OB, Spritzer LE, et al. Demonstration of dural sinus occlusion by use of MR angiography. AfNR Am ₹ Neuroradiol 1990;11:199-201.

82 Mattle HP, Wentz KV, Edelman RR, Wallner B, Finn $\mathrm{JP}$, Barnes $\mathrm{P}$, et al. Cerebral venography with MR. Radiology 1991; 178:453-8.

83 Isewsee $\mathrm{CH}$, Reul J, Throw A. Magnetic resonance imaging of thrombosed dural sinuses. Stroke 1994;25: 29-34.

84 Padayachee TS, Bingham JB, Craves MT, Colchester AC, Cox TC. Dural sinus thrombosis: diagnosis and follow up by magnetic angiography and imaging. Neuroradiology 1991;33:165-7.

85 Creasy J, Price RR, Presbery T, Goins D, Partain CL, Kessler RM. Gadolinium enhanced MR angiography. Radiology 1990;175:280-3.

86 Polak JF, Kalina P, Donaldson MC, O'Leary DH, Whittemore AD, Mannick JA. Carotid endarterectomy: pre-operative evaluation of candidates with combined doppler sonography and MR angiography. Work in progress. Radiology 1993;186:333-8.

87 Young GR, Humphreys PRD, Shaw MDM, Nixon TE, Smith ETS. Comparison of magnetic resonance angiography, duplex ultrasound, and digital subtraction angiography in assessment of extra cranial internal carotid artery stenosis. ҰNNP 1995 (in press)

88 Schwartz RB, Towes KM, Chernoff DM, et al. Common carotid bifurcation: evaluation with spiral CT. Radiology 1992;185:513-9.

89 Kallender WA, Polakin A. Physical performance characteristics of spiral CT scanning. Med Phys 1991;18: 910-5.

90 Seldinger SI. Catheter replacement of the needle in percutaneous arteriography. Acta Radiol 1953;39:368-76.

91 Hankey GT, Warlow CP, Sellar RJ. Cerebral angiographic risk in mild cerebro-vascular disease. Stroke 1990;21:209-22.
92 Jeans WD, Mackenzie S, Baird RN. Angiography in transient cerebral ischaemia using three views of the carotid bifurcation. Br ₹ Radiol 1986;59:135-42.

93 Chikos PM, Fisher CD, Hirsch JH, Harley TD, Thiele BC, Strandness DE Jr. Observer variability in evaluating extra cranial carotid artery stenosis. Stroke 1983;14 885-92.

94 Goldstein ST, Fried AM, Young B, Tibbs PA. Limited usefulness of aortic arch angiography in the evaluation of carotid occlusive disease. AfR Am F Roentgenol 1982; 138:103-8.

95 Moseley I. Diagnostic imaging in neurological disease. Edinburgh: Churchill Livingston, 1986:125.

96 Schuler TJ, Flanigan P, Lim CT, Keifer T, Williams LR, Behrend AJ. The affect of carotid syphon stenosis on stroke rate death and relief of symptoms following on stroke rate death and relief of symptoms following
elective carotid endorterectomy. Surgery 1982;92: elective

97 Mastos MA, Van Bemmelen PS, Hodgson KJ, Berkmeter $C D$, Ramsay DE, Sumner DS. The influence of carotid siphon stenosis on short and long term outcome after carotid endartectomy: fact or fiction [abstract]. $\mathcal{F}$ Vasc Surg 1992;16:475.

98 Markus H. Transcranial Doppler detection of circulating cerebral emboli. Stroke 1993;24:1246-50.

99 Grzyska V, Freitag J, Zeumer H. Selective cerebral interarterial DSA Complication rate and control of risk factors. Neuroradiology 1990;32:296-9.

100 Waugh JR, Sacharias N. Arteriographic complications in the DSA era. Radiology 1992;182:293-246.

101 Davies KN, Humphrey PR. Complications of cerebral angiography in patients with symptomatic carotid territory ischaemia. $\mathcal{F}$ Neurol Neurosurg Psychiatry 1993;

102 Baum S, Stein G, Kuroda KK. Complications of 'no arteriography'. Radiology 1966;86:835-8.

103 Wood GW, Lukin RR, Tomsick TA, Chambers AA Digital subtraction angiography with intravenous injection; assessment of 1000 carotid bifurcations. $A \mathcal{F R ~} A m^{\mathcal{F}}$ Roentgenol 1983;140:855-9.

104 Ducos de Lahitte M, Marc-Vergnes JP, Rascol A, Guiraud B, Manelfe C. Intravenous angiography of the extracranial cerebral arteries. Radiology 1980;137: 705-11.

105 Cebul RD, Paulus RA. The failure of intravenous digita subtraction angiography in replacing carotid angiosubtraction angiography in replacing car

106 Turner WH, Murie JA. Intravenous digital subtraction angiography for extra cranial carotid artery disease. $\mathrm{Br} \mathcal{F}$ Surg 1989;76:1247-50.

107 Hankey GJ, Warlow CP. Transient ischaemic attacks of the brain and eye. London: WB Saunders, 1994:269.

108 Kricheff I. Angiographic investigation of cerebral aneurysms. Neuroradiology 1972;105:72-5.

109 Forster DMC, Steiner L, Hakanson S, Bergvall U. The value of repeat pan angiography in cases of unexplained subarachnoid haemorrhage. 7 Neurosurg 1978;48: $712-6$.

110 Moseley I. Diagnostic imaging in neurological disease. Edinburgh: Churchill Livingstone, 1986:104.

111 Wolpert SM, Caplan LR. Current role of cerebral angiography in the diagnosis of cerebrovascular disease. angiography in the diagnosis of cerebro

112 Heiserman JE, Dean BC, Hodak JA, et al. Neurologic complications of cerebral angiography. AfNR $\mathrm{Am} \mathcal{f}$ Neuroradiol 1994;15:1401-7.

113 Maurice William RS. Subarachnoid haemorrhage. Bristol: Wright; 1987:135.

114 Higashida, Halback V, Hieshena GB, Endovascular therapy of aneurysms. Interventional neuroradiology. New York: Raven Press, 1992:51-72.

115 Guglielmi G, Vinveza F, Sepetka I, et al, Electrothrombosis of saccular aneurysms via endo vascular approach Part 1: electrochemical basis, technique, and experimental results. $¥$ Neurosurg 1991;75:1-7.

116 Spetzler RF, Martin NA. A proposed grading system for arteriovenous malformation. $f$ Neurosurg $1986 ; 65$ : arteriove

117 Berenstein A, Lasjaunias P. Surgical neuro angiography. 4. Endovascular treatment of cerebral lesions. Berlin: Springer Verlag, 1992:27;25-80.

118 Burrows EH, Leeds NE. Vascular abnormalities in neuroradiology. New York: Churchill Livingston 1981 75-117.

119 Brandt-Zawadzki M, Anderson M, De Armour SJ, et al. Radiation-induced large intra cranial vessel occlusive vasculopathy. $A \mathcal{F}$ Am $\mathcal{F}$ Roentgenol 1980;134:51-5.

120 Newton TH, Potts DF. Radiology of the skull and brain angiography. Saint Louis; CV Mosby 1974, P 1707.

121 Anson J, Crowell RM. Cerviocranial arterial dissection. Neurosurgery 1991;29:89-96.

122 Newton TH, Potts DF. Radiology of the skull and brain angiography. St Louis: CV Mosby, 1974:939-45.

123 Hankey GJ, Warlow CP. Cost effective investigation of patients with suspected transient ischaemic attacks. patients with suspected transient ischaemic
$\Im$ Neurol Neurosurg Psychiatry 1992;55:171-6. 